\title{
Role of mitogen-activated protein kinas in Zn-BC-AM PDT-induced apoptosis in nasopharyngeal carcinoma cells
}

${ }^{1}$ Department of Q2 $^{2}$ Biology, Hong Kong Baptist University, Hong Kong

${ }^{2}$ Department of Biochemistry, The Hong Kong University of Science and Technology, Hong Kong

${ }^{3}$ Department of Biology and Center for Cancer Research, The Hong Kong University of Science and Technology, Hong Kong

${ }^{4}$ Department of Chemistry, The Hong Kong University of Science and Technology, Hong Kong

Photodynamic therapy (PDT) with a recently developed photosensitizer Zn-BC-AM was found to effectively induce apoptosis in a welldifferentiated nasopharyngeal carcinoma (NPC) HK-1 cell line. Sustained activation of p38 mitogen-activated protein kinase (MAPK) and cjun N-terminal kinase (JNK) as well as a transient increase in activation of extracellular-regulated kinase (ERK) were observed immediately after Zn-BC-AM PDT. A commonly used p38 MAPK/JNK pharmacological inhibitor PD169316 was found to reduce PDT-induced apoptosis of HK-1 cells. PD169316 also prevented the loss of Bcl-2 and Bcl-xL in PDT-treated HK-1 cells. However, inhibition of JNK with SP600125 had no effect on Zn-BC-AM PDT-induced apoptosis while inhibition of ERK with PD98059 or p38 MAPK with SB203580 significantly increased Zn-BC-AM PDT-induced apoptosis. Further study showed that knockdown of the p38 $\beta$ isoform with siRNA also increased Zn-BCAM PDT-induced apoptosis, indicating that the anti-apoptotic effect of PD169316 in PDT-treated HK-1 cells was probably independent of p38 MAPK or JNK activation. Taken together, the results suggest that inhibition of p38 $\beta$ and ERK may enhance the therapeutic efficacy of ZnBC-AM PDT on NPC cells. It should be noted that data only based on the use of PD169316 should be interpreted in caution. Copyright (C) 2010 John Wiley \& Sons, Ltd.

KEY WORDS - apoptosis; MAPK; p38; isoforms; PD169316; photodynamic therapy

ABBREVIATIONS - DIC, differential interference contrast; NPC, nasopharyngeal carcinoma; Zn-BC-AM, Zinc (II) 2,3,8,8,12,13,17,18octaethylbenzochlorin amidinium;

* Correspondence to: N. K. Mak, Department of Biology, Hong Kong Baptist University, 224, Waterloo Road, Hong Kong. Tel: (862) 34117059. E-mail:nkmak@hkbu.edu.hk

${ }^{\dagger}$ Present address: Department of Clinical Oncology, University of Hong Kong, Hong Kong.

\section{INTRODUCTION}

Mitogen $^{\text {Q3 }}$-activated protein kinases (MAPKs), a group of protein kinases activated by dual phosphorylation, are involved in controlling the growth, differentiation, movement and death of cell in response to various stimuli and stresses. ${ }^{1}$ There are three major groups of MAPKs produced by the mammalian cells, namely p38 MAPK, c-jun $\mathrm{N}$ terminal kinases (JNK) and extracellular signal regulated kinases $\left(\underline{E R K s}{ }^{Q 4}\right)$. ERK is generally involved in the regulation of proliferation while p38 MAPK and JNK are frequently activated and participated in stress responses and programmed cell death. ${ }^{2-4}$ As deregulation of MAPKs signalling pathways is known to play a role in neoplastic transformation and tumour progression, chemotherapeutic agents targeting on these pathways are currently under development for the treatment of cancer or to improve response to conventional therapy.

Photodynamic therapy (PDT) is a promising therapeutic approach for cancer management. In the past decade, various types of photosensitizers were developed and evaluated for their efficacy in tumour eradication. It is now clear that the target of PDT is not restricted to a single cellular component or a single signalling pathway. Multiple intracellular components and signalling pathways have been implicated in PDT-induced cell death. ${ }^{5}$ The role of MAPKs in PDT-induced apoptosis has not been fully studied. ${ }^{6,7}$ Photoactivation of $\mathrm{Pc} 4$ was found to induce phosphorylation of p38 MAPK in CHO cells. ${ }^{8}$ Similar findings were also observed in human adenocarcinoma HeLa cells with hypericin-PDT, ${ }^{9}$ human keratinocytes HaCat cells and hypopharyngeal carcinoma FaDu cells treated with ALAPDT, ${ }^{10,11}$ murine keratinocytes Pas 212 cells treated with benzoporphyrin derivative-PDT ${ }^{12}$ and also human leukaemia HL60 and murine mammary carcinoma 4T1 cells treated with PORF-TEG-PDT. ${ }^{13}$ A previous study showed that Rose Bengal PDT-activated JNK was required for caspase-3 activation in the A431 carcinoma cells. ${ }^{14}$ In contrast, TPPS2a PDT-activated JNK was found to play a 
role in providing survival signals to PDT-treated epithelial ovarian cancer cells. ${ }^{15}$ In LFS087 and GM38A cell lines, ERK was transiently activated by Photofrin PDT, ${ }^{16}$ whereas ERK was not affected in another PDT model. ${ }^{12}$ Therefore, the action of PDT on the activities of MAPKs was probably cell line and photosensitizer-dependent.

We have previously demonstrated that Zn-BC-AM PDT induces apoptosis in NPC cells. ${ }^{17}$ In the present study, we aim to study the role of MAPKs in Zn-BC-AM PDT-induced apoptosis by using specific pharmacological inhibitors and siRNA for various p38 MAPK isoforms. We found that knockdown the expression of $\mathrm{p} 38 \beta$, but not $\mathrm{p} 38 \alpha$ and $\mathrm{p} 38 \delta$ isoform, would enhance Zn-BC-AM PDT-induced apoptosis. We also demonstrated the discrepancy in apoptosis enhancing effect of two commonly used inhibitors PD169316 and SB203580 in Zn-BC-AM PDT-induced apoptosis of NPC cells.

\section{MATERIALS AND METHODS}

\section{Materials}

Inhibitors of p38 MAPK (SB203580), p38 MAPK/JNK (PD169316), JNK (SP600125) and MEK/ERK (PD98059) were purchased from Calbiochem. Antibodies against p38 $\alpha$ MAPK, p38 $\beta$ MAPK, p38 $\delta$ MAPK, phospho-p38 MAPK (pp38) (Thr180/Tyr182), p38 MAPK (p38), phospho-SAPK/ JNK (p-JNK) (Thr183/Tyr185), SAPK/JNK (JNK), phospho-p44/42 MAPK (p-ERK) (Thr202/Tyr204), p44/42 MAPK (ERK), Bcl-xL, Bad, Bax, Bid, caspase-3, -8, -9 and $\beta$-actin were purchased from Cell Signalling Technology. Bcl-2 antibody was purchased from Dako. Stock solution of the photosensitizer $\mathrm{Zn}-\mathrm{BC}-\mathrm{AM}^{17}$ was prepared in DMSO.

\section{Cell culture}

HK-1 cells ${ }^{18}$ were maintained in RPMI 1640 medium (GIBCO) supplemented with $10 \%$ FBS (GIBCO) and antibiotics penicillin $(50 \mu \mathrm{g} / \mathrm{ml}) /$ streptomycin $(50 \mu \mathrm{g} / \mathrm{ml})$ (GIBCO). The cells were maintained and incubated in a humidified $5 \% \mathrm{CO}_{2}$ incubator at $37^{\circ} \mathrm{C}$.

\section{Zn-BC-AM PDT treatment}

Except otherwise stated, HK-1 cells $\left(3 \times 10^{5}\right.$ cells/dish $)$ were incubated overnight in $35 \mathrm{~mm}$ petri dish. Zn-BC-AM $(1 \mu \mathrm{M})$ was then added and the cells were incubated at $37^{\circ} \mathrm{C}$ in dark for $24 \mathrm{~h}$. Medium containing $\mathrm{Zn}-\mathrm{BC}$-AM was replaced with fresh medium before light irradiation. The NPC cells were irradiated at an intensity of $0.8 \mathrm{~mW} / \mathrm{cm}^{2}$ from a projector equipped with a 400-Watt tungsten lamp, a heat isolation filter and narrow band filter $(682 \pm 5 \mathrm{~nm})$. After light irradiation, the cells were incubated in a $5 \% \mathrm{CO}_{2}$ incubator at $37^{\circ} \mathrm{C}$ until further investigation.

\section{Propidium $^{Q 5}$ iodide exclusion assay}

Cell viability was determined by propidium iodide exclusion assay. Both adherent and floating cells were collected at $24 \mathrm{~h}$
post-PDT. The cells were then incubated with propidium iodide (PI, $5 \mu \mathrm{g} / \mathrm{ml}$ in PBS) in dark for $5 \mathrm{~min}$. The cells were then immediately analysed by FACSCalibur (Becton Dickson) with the excitation wavelength at $488 \mathrm{~nm}$. Fluorescent signals were collected by the FL-2 channel. Data were further analysed by the CellQuest software.

\section{Clonogenicity assay}

Viability of PDT-treated NPC cells was evaluated by the clonogenicity assay. ${ }^{19}$ Briefly, the cells were trypsinized and collected by centrifugation $(700 \mathrm{~g}, 5 \mathrm{~min})$ after PDT. Various concentrations of cells were seeded onto $35 \mathrm{~mm}$ petri dishes and colony formation was determined 7 days after incubation. The cell monolayers were then washed twice with PBS and fixed with absolute methanol for $10 \mathrm{~min}$. The cells were stained with $0.5 \%$ of crystal violet for $10 \mathrm{~min}$ and rinsed four times with tap water. The stained cells were allowed to air-dry. The images and the number of colonies in each dish were captured and analysed with software Quantity-One (Bio-Rad).

\section{Nucleus staining with Hoechst 33342}

HK-1 cells were grown on coverslip placed in $35 \mathrm{~mm}$ petri dish and subjected to PDT as described above. At the desired time point, the cells were stained with $20 \mu \mathrm{g} / \mathrm{ml}$ of Hoechst 33342 (Fluka, Allentown) for $30 \mathrm{~min}$. Floating cells were collected and washed twice with PBS and collected by centrifugation $(700 \mathrm{~g}, 5 \mathrm{~min})$. Both adherent and floating cells were pooled and observed under the fluorescence microscope. The percentage of apoptotic cells was determined by counting at least 300 cells for each treatment group.

\section{Western blot analysis}

After PDT, total cell lysate was prepared by lysing the cells with lysis buffer containing $50 \mathrm{mM}$ Tris- $\mathrm{HCl} \mathrm{pH} 8.0$, $150 \mathrm{mM} \mathrm{NaCl}, 1 \% \mathrm{NP}-40$ (USB), $1 \%$ phosphatase inhibitors cocktail (Calbiochem) and $0.25 \%$ protease inhibitors cocktail (Sigma). Cell debris was removed by centrifuging the cell lysates at $10000 \mathrm{~g}$ at $4{ }^{\circ} \mathrm{C}$ for $10 \mathrm{~min}$. The protein concentrations were determined using the detergent compatible protein assay kit (Bio-Rad). Cellular proteins were then electrophoretically fractionated by SDS-PAGE. The separated proteins were electro-blotted to polyvinylidene difluoride membrane (PVDF, Perkin Elmer) in a transfer buffer containing $50 \mathrm{mM}$ Tris, $150 \mathrm{mM}$ glycine, $0.05 \%$ SDS and $20 \%$ methanol. The membrane was blocked in $5 \%$ nonfat dry milk in TBST ( $25 \mathrm{mM}$ Tris, $140 \mathrm{mM} \mathrm{NaCl}, 3 \mathrm{mM}$ $\mathrm{KCl}$ and $0.1 \%$ Tween 20). The membrane was then incubated sequentially with an appropriately diluted primary antibody for $2 \mathrm{~h}$ and secondary antibody conjugated with horseradish peroxidase (HRP) for $1 \mathrm{~h}$ at room temperature. Chemiluminescence was detected using the WESTSAVE $\mathrm{Up}^{\mathrm{TM}}$ (Abfrontier) and visualized on an X-ray film. Quantity 
One software (Bio-rad) was used to measure the densitometry of bands generated from Western blot analysis.

\section{Transfection with plasmid DNA}

HK- 1 cells $\left(3 \times 10^{5}\right.$ cells $)$ were seeded in $35 \mathrm{~mm}$ petri dish the day before transfection and maintained in complete medium. $3.75 \mu$ l of Lipofectamine ${ }^{\mathrm{TM}} 2000$ (Invitrogen) was added in $200 \mu \mathrm{l}$ serum free medium and then incubated at room temperature for $5 \mathrm{~min}$. $1.6 \mu \mathrm{g}$ of $\mathrm{Bcl}-2$ pcDNA3 plasmid (Addgene plasmid 8768) was added to another $200 \mu \mathrm{l}$ of serum-free medium. ${ }^{20}$ Transfection complex $(400 \mu \mathrm{l})$ was then prepared by mixing $200 \mu \mathrm{l}$ plasmid DNA to $200 \mu \mathrm{l}$ Lipofectamine $2000^{\mathrm{TM}}$ and the mixture was allowed to incubate for further $30 \mathrm{~min}$. During the period of incubation, the cells were replaced with $1.6 \mathrm{ml}$ of fresh serum-free medium. The transfection complex was transfected to cells and incubated for $6 \mathrm{~h}$. The transfection complex was then removed, replaced with fresh complete medium and incubated for overnight. Same amount of pcDNA3.1 empty vector was used as an internal control and transfected the cells as described above.

\section{siRNA transfection}

HK-1 cells $\left(1.5 \times 10^{5}\right)$ were seeded in $35 \mathrm{~mm}$ petri dish the day before transfection and maintained in complete medium. To prepare the transfection complex, $3.75 \mu$ l of Lipofectamine TM 2000 (Invitrogen) was added to $200 \mu \mathrm{l}$ serum free medium and the mixture was incubated at room temperature for $5 \mathrm{~min} .3 .3 \mu \mathrm{l}$ of $20 \mu \mathrm{M}$ siRNA was added to another $200 \mu \mathrm{l}$ of serum-free medium. Transfection complex $(400 \mu \mathrm{l})$ was prepared by adding the siRNA to the Lipofectamine $2000^{\mathrm{TM}}$ and the mixture was allowed to incubate for further $30 \mathrm{~min}$. Before transfection, the cells were replaced with $1.6 \mathrm{ml}$ of serum-free medium. The transfection complex was transfected to cells and the mixture was incubated for $6 \mathrm{~h}$. The transfection mixture was then removed, replaced with complete medium and then incubated overnight. Same amount of non-targeting siRNA was used as an internal control and transfected to the cells as described above. The antisense sequences of siRNA were: p3 $8 \alpha$ MAPK (5' - GGA AUU CAA UGA UGU GUA UUU3', 5' - UCU CCG AGG UCU AAA GUA UUU-3', 5' - GUA AUC UAG CUG UGA AUG AUU- $3^{\prime}$ and $5^{\prime}-$ GUC CAU CAU UCA UGC GAA AUU-3'), p38 $\beta$ MAPK (5'- GCC CUG AGG UUC UGG CAA AUU-3', 5' - CGA CGA GCA CGU UCA AUU CUU-3', 5' - CCA UAG ACC UCC UUG GAA GUU-3' and 5'- GCG CCG ACC UGA ACA ACA UUU- $\left.3^{\prime}\right), \mathrm{p} 38 \delta$ MAPK (5'- GCU CAA AGG CCU UAA GUA CUU- $3^{\prime}, 5^{\prime}$ - GGA GUG GCA UGA AGC UGU AUU$3^{\prime}, 5^{\prime}$ - GGA UUU CAC UCA GCU GUU CUU-3' and 5'GCC GUU UGA UGA UUC CUU AUU-3') and nontargeting pool ( $5^{\prime}$ - UGG UUU ACA UGU CGA CUA A-3', 5' - UGG UUU ACA UGU UGU GUG A-3' ${ }^{\prime}, 5^{\prime}$ - UGG UUU ACA UGU UUU CUG A-3' and $5^{\prime}$ - UGG UUU ACA UGU UUU CCU A-3').

\section{Statistical analysis}

All graphs were plotted and analysed by the software Microsoft Excel, SigmaPlot and SPSS. Statistical significance $(p<0.05)$ was determined using Student's $t$-test.

\section{RESULTS}

Zn-BC-AM PDT-induced cell death and apoptosis in HK-1 cells

The viability of Zn-BC-AM PDT-treated HK-1 cells was firstly evaluated by the assessment of the integrity of cell membrane and the ability of the treated cells for colony formation. The results showed that the percentage of PI stained cells was increased in a drug and light-dose dependent manner (Figure 1A). At the concentration of $1 \mu \mathrm{M}, \mathrm{Zn}$-BC-AM PDT also effectively reduced the colony formation in a light dose-dependent manner, indicating that Zn-BC-AM PDT-treated HK-1 cells underwent irreversible cell damage (Figure 1B). To determine whether Zn-BC-AM PDT induced apoptotic cell death in HK-1 cells, the morphological changes and the downstream apoptotic biomarkers were examined. Cell shrinkage and plasma membrane blebbing were observed in cells at 2 and $4 \mathrm{~h}$ postPDT. Chromatin condensation (Figure 1C), one of the features of apoptotic nuclei, was also observed. In addition, proteolytic cleaved fragments of the apoptotic initiator caspase-9 (MW: 37 and 35) and apoptotic executioner caspase-3 (MW: 19 and 17) were detected at 0.5-8 h postPDT. The appearance of the cleaved fragments of caspase- 8 (MW: 43 and 41) was also observed at $2 \mathrm{~h}$ post-PDT (Figure 1D).

\section{Involvement of Bcl-2 family proteins in $\mathrm{Zn}-\mathrm{BC}-\mathrm{AM}$ PDT-induced apoptosis}

We further characterized the expression levels of antiapoptotic (Bcl-2, Bcl-xL) and pro-apoptotic Bcl-2 family proteins (Bad, Bid and Bax) in Zn-BC-AM PDT-treated HK1 cells. Results from the Western Blot analysis (Figure 2A) of whole-cell lysates revealed an immediate reduction (i.e. post-PDT, 0 hr) of Bcl-2, Bcl-xL and Bad after Zn-BC-AM PDT. The level of Bid started to decrease at $4 \mathrm{~h}$ post-PDT. However, the activated form of Bid (truncated Bid, tBid) was not detected in the PDT-treated cells. In contrast, the protein level of Bax remained unchanged between 0 and $8 \mathrm{~h}$ postPDT. To further establish the role of Bcl-2 in HK-1 cells, Bcl-2 was overexpressed before PDT. Overexpression of $\mathrm{Bcl}-2$ resulted in a significant reduction of apoptosis in $\mathrm{HK}-1$ cells (Figure 2B). The percentage of apoptotic cells was reduced from 60 to $40 \%(p<0.05)$. Overexpression of Bcl-2 also reduced the expression level of cleaved caspase- 3 in PDT-treated HK-1 cells (Figure 2C). This observation clearly indicated that overexpression of $\mathrm{Bcl}-2$ would reduce PDT-induced apoptosis of HK-1 cells. 


\section{Activation of MAPKs in Zn-BC-AM PDT-treated HK-1 cells}

To determine whether Zn-BC-AM PDT activated the phosphorylation of MAPKs, the states of phosphorylation of p38 MAPK, JNK and ERK were analysed (Figure 3). A very low background level of p-p38 was detected in the untreated HK-1 and Zn-BC-AM-treated HK-1 cells. An apparent increase in p-p38 was observed immediately after $\mathrm{Zn}$-BC-AM PDT. The time course of increase in p-JNK was similar to p-p38. In contrast, constitutive expression of $\mathrm{p}$ ERK was observed in the untreated HK-1 cells. A transient increase followed by a decrease of the p-ERK was observed after Zn-BC-AM PDT. The p-ERK signal was restored to the control level at $4 \mathrm{~h}$ post-PDT. The restoration of $\mathrm{p}$-ERK expression might be derived from the surviving cells.

\section{PD169316 reduced Zn-BC-AM PDT-induced apoptosis}

PD169316 is a general use p38 MAPK/JNK dual inhibitor. The effect of increasing concentrations of PD169316 on the

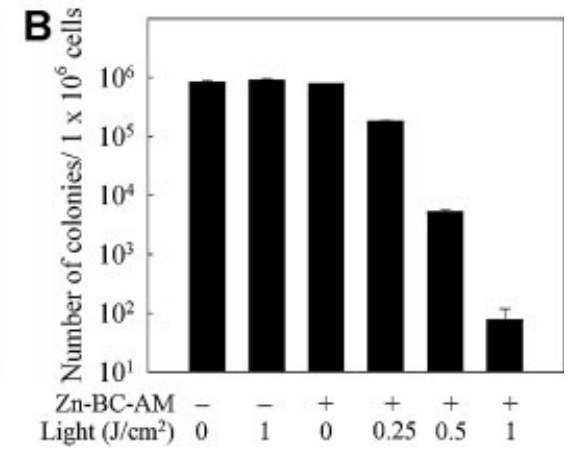

phosphorylation of p38 MAPK and JNK induced by Z AM PDT was firstly examined. A dose dependent inhibition of phosphorylation of p38 MAPK and JNK by PD169316 was observed in PDT-treated HK-1 cells (Figure 4A). At the concentrations of 1-2.5 $\mu \mathrm{M}, \mathrm{PD} 169316$ was found to have a greater inhibitory effect on the production of p-p38 MAPK than p-JNK. A higher concentration of PD169316 (5$10 \mu \mathrm{M}$ ) was needed to inhibit the phosphorlyation of JNK induced by Zn-BC-AM PDT. Under the same experimental condition, PD169316 (1-10 $\mu \mathrm{M})$ also dose dependently reduced the percentage of apoptotic cells in PDT-treated HK-1 cells (Figure 4B). The anti-apoptotic effect of PD169316, as judged from the reduction of the cleaved caspase-9, -8 and -3, was also observed (Figure 4C). Previous studies have shown that MAPK phosphorylation may impair the anti-apoptotic function of Bcl-2 family proteins and result in apoptotis. As PD169316 was found to inhibit phosphorylation of p38 MAPK and JNK, we further examined the effect of PD169316 on the expression of antiapoptotic Bcl-2 proteins (Figure 4D). PDT significantly reduced the expression level of Bcl-2 (Figure 4E) and Bcl- 
A

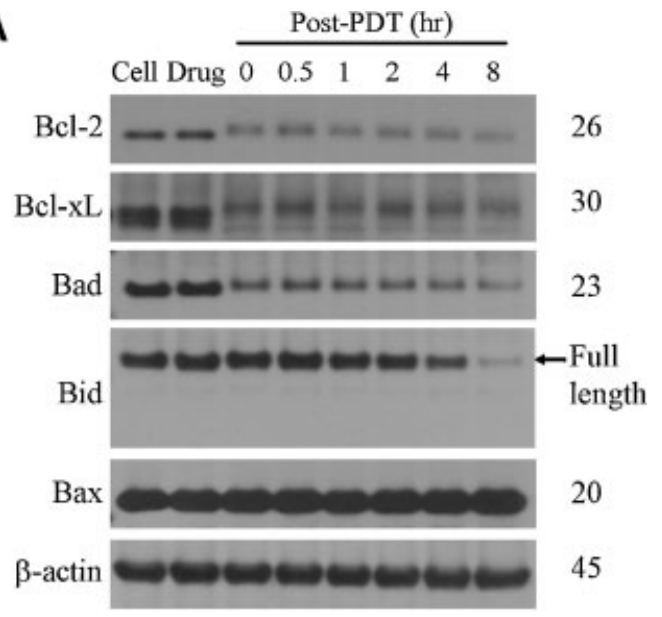

B
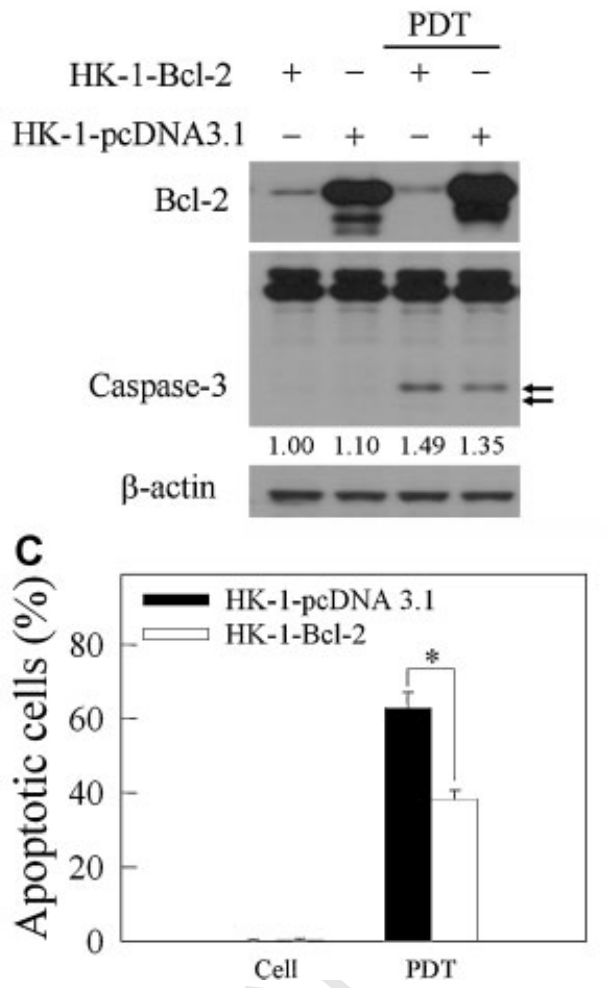

Figure 2. Expression of Bcl-2 family member proteins in $\mathrm{Zn}-\mathrm{BC}-\mathrm{AM}$ PDT-treated HK-1 cells. HK-1 cells were incubated with Zn-BC-AM $(1 \mu \mathrm{M})$ for $24 \mathrm{~h}$. The cells were then irradiated with a light dose of $1 \mathrm{~J} /$ $\mathrm{cm}^{2}$ as described in Materials and Methods. (A) Kinetics of Bcl-2 family protein expressions after PDT. (B) Effect of Bcl-2 overexpression on the proteolytic cleavage of caspase-3 after PDT. Cell lysates were prepared at $4 \mathrm{~h}$ post-PDT. (C) Bcl-2 overexpression reduced PDT-induced apoptosis of HK-1 cells. The percentage of apoptotic cells was counted at $4 \mathrm{~h}$ post-PDT. At least 400 cells were counted for each group. Results were expressed as the mean $\pm \mathrm{SD}(n=3) .{ }^{*} p<0.05$ versus PDT in HK-1-pcDNA 3.1.

xL (Figure 4F) in HK-1 cells. In the presence of PD169316, the expression level of $\mathrm{Bcl}-2$ and $\mathrm{Bcl}-\mathrm{xL}$ was restored. Taken together, these observations suggested that PD169316 may reduce PDT-induced apoptosis via the early inhibition of phosphorylation of p38 MAPK and JNK, reduction of PDT-

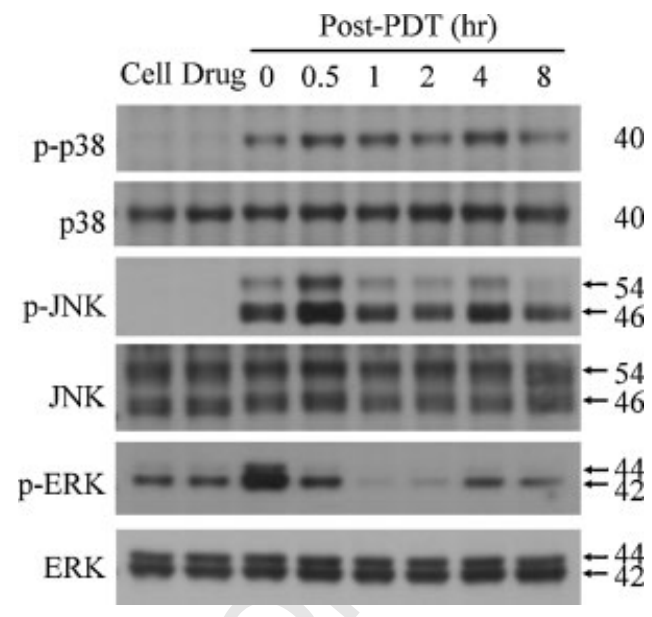

Figure 3. Kinetics of MAPKs activation induced by Zn-BC-AM PDT. HK-1 cells were incubated with $\mathrm{Zn}$-BC-AM $(1 \mu \mathrm{M})$ for $24 \mathrm{~h}$, followed by irradiation with light dose of $1 \mathrm{~J} / \mathrm{cm}^{2}$ as described in Materials and Methods.

induced photodamage of anti-apoptotic Bcl-2 proteins and the subsequent proteolytic cleavage and activation of downstream effector caspases.

Contribution of p38 MAPK and JNK to Zn-BC-AM PDT-induced apoptosis in HK-1 cells

Since Zn-BC-AM PDT was found to induce the phosphorylation activation of p38 MAPK, JNK and ERK in HK1 cells, specific kinase pharmacological inhibitors were used to evaluate the effect of p38 MAPK, JNK and ERK inhibition on the formation of apoptotic cells after $\mathrm{Zn}-\mathrm{BC}$ AM PDT. We pre-treated the HK-1 cells with different doses of PD169316 (10-40 $\mu \mathrm{M}), \quad$ SB203580 (10-40 $\mu \mathrm{M}$, a preferential p38 MAPK inhibitor) or SP600125 (5$20 \mu \mathrm{M}$, a preferential JNK inhibitor), for $1 \mathrm{~h}$ before light exposure $\left(1-2 \mathrm{~J} / \mathrm{cm}^{2}\right)$. The inhibitor was retained in the medium until sample harvesting. Apoptosis was then enumerated at $4 \mathrm{~h}$ post-PDT (Figure 5). The percentage of apoptotic cells in the control and various MAPK inhibitorstreated HK-1 cells was less than 4\%. PD169316 (10 $\mu \mathrm{M})$ was found to reduce the percentage of apoptosis at the light dose of $1-2 \mathrm{~J} / \mathrm{cm}^{2}$ (Figure $5 \mathrm{~A}$ ) and the inhibition was in a drug dose-dependent manner (Figure 5B). As PD169316 is a dual p38 MAPK/JNK inhibitor, it is logically to deduce that SB203580 and SP600125 may also reduce PDT-induced apoptosis of HK-1 cells to a certain extent. However, SB203580 $(10 \mu \mathrm{M})$ was found to enhance the percentage of apoptosis of PDT-treated HK-1 cells (Figure 5C and 5D). Furthermore, apoptosis was not affected by the JNK inhibitor SP600125 (Figure 5E and 5F).

To further confirm the actions of PD169316, SB203580 and SP600125, we checked for the state of phosphorylation of p38 MAPK and JNK in PDT-treated HK-1 cells. As shown in Figure 5G, an increased in the expression level of p-p38 p-JNK was observed at $10 \mathrm{~min}$ post-PDT. The expression of both p-p38 and p-JNK could be reduced by PD169316. The phosphorylation of their downstream target 


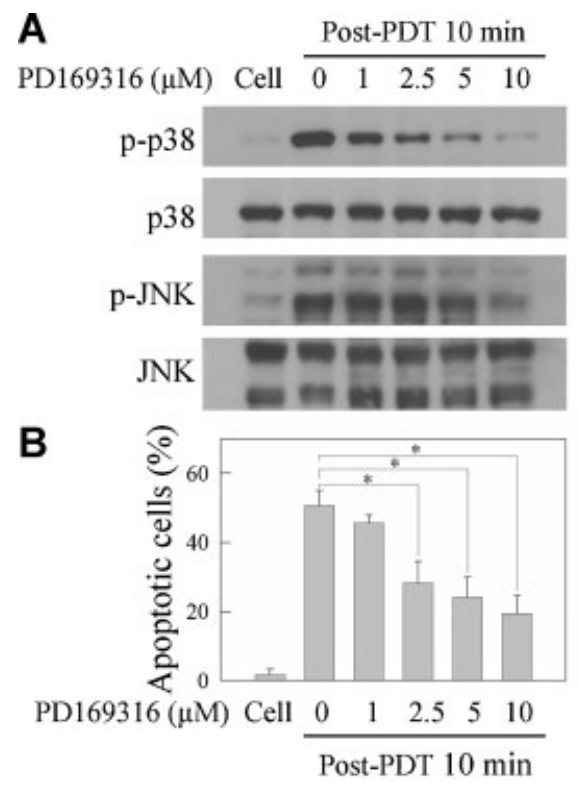

C

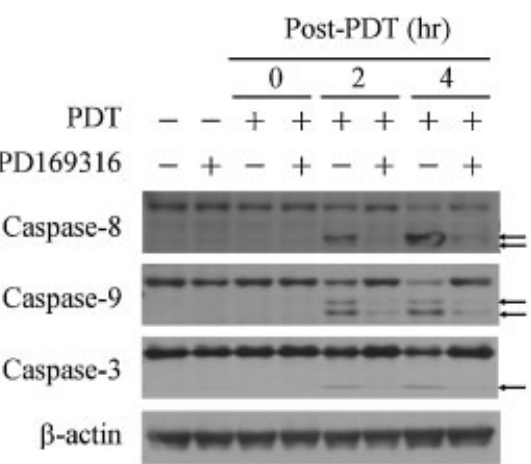

D
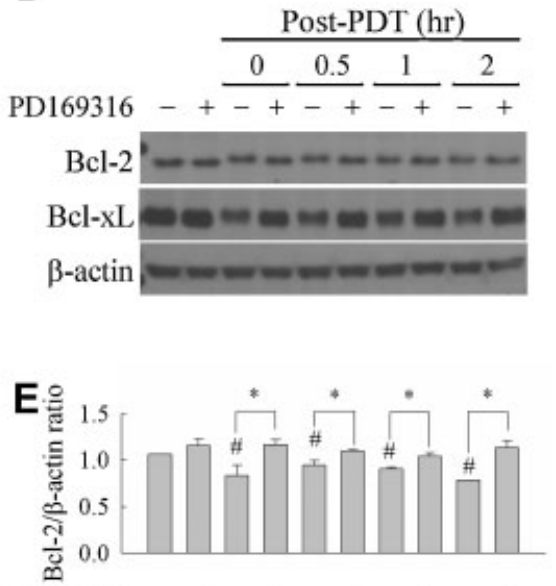

PD169316 - $\frac{\frac{-+}{0} \frac{-+}{0.5} \frac{-+}{1} \frac{-+}{2}}{\text { Post-PDT (hr) }}$

$F$ 을

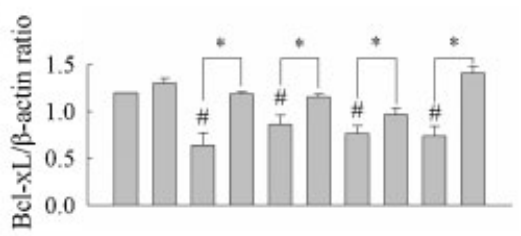

PD169316 - + $\frac{\frac{-+}{0} \frac{-+}{0.5} \frac{-+}{1} \frac{-+}{2}}{\text { Post-PDT (hr) }}$

Figure 4. Reduction of Zn-BC-AM PDT-induced apoptosis by PD169316. HK-1 cells $\left(3 \times 10^{5}\right)$ in 35 mm petri dish were treated with Zn-BC-AM ( $1 \mu$ M) as described in Materials and Methods. Before light irradiation $\left(1 \mathrm{~J} / \mathrm{cm}^{2}\right)$, the cells were treated with various concentrations of PD169316. (A) Dose dependent inhibition of production of p-p38 and p-JNK at 10 min post-PDT. (B) Reduction of proteolytic cleavage of caspase-8, -9 and -3 by PD169316. (C) Reduction of PDT-induced formation of apoptotic cells. At least 400 cells were counted for each group. The percentage of apoptotic cells was expressed as the mean \pm SD $(n=3) .{ }^{*} p<0.05$ versus PDT alone. (D) Western blotting analysis of Bcl-2 and Bcl-xL expression. Cell lysates were prepared at 0-2 h post-PDT. (E) and (F) Statistical analysis on the ratios between Bcl- 2 or Bcl-xL and $\beta$-actin in cells with or without PD169316 treatment. \# $p<0.05$ versus untreated cell control; ${ }^{*}$ $p<0.05$ versus PDT.

ATF-2 was also reduced. Similarly, the expression of p-p38 (Figure 5H) and p-JNK (Figure 5I) was reduced by their respective inhibitor SB203580 and SP600125 in HK-1 cells.

\section{Transient knockdown of p38 $\beta$ isoform enhanced Zn-BC-AM PDT-induced apoptosis}

Since PD169316 and SB203580 exerted an opposing effect on PDT-induced apoptosis of HK-1 cells, we applied the siRNA knockdown technology to dissect the role of p38 MAPK on Zn-BC-AM PDT-induced apoptosis. Four p38 MAPK isoforms were previously identified in mammalian cells, namely $\mathrm{p} 38 \alpha,{ }^{21} \mathrm{p} 38 \beta,{ }^{22} \mathrm{p} 38 \delta,{ }^{23}$ and $\mathrm{p} 38 \gamma{ }^{24}$ Since the expression of $\mathrm{p} 38 \gamma$ is restricted in skeletal muscle, heart, thymus and testis, ${ }^{25,26}$ the role of $\mathrm{p} 38 \alpha, \mathrm{p} 38 \beta$ and $\mathrm{p} 38 \delta$ in Zn-BC-AM PDT-induced apoptosis of HK-1 cells was examined using siRNA specifically for the expression of these three p38 MAPK isoforms. In the control experiment, siRNA specifically reduced the expression of their corresponding target (Figure 6A). The formation of apoptotic cells was then determined (Figure 6B). Only HK- 1 cells transfected with siRNA of $\mathrm{p} 38 \beta$ enhanced the percentage of apoptotic cells $(83.1 \%, p<0.05)$ after PDT (Figure 6C). Knockdown of either p38 $\alpha$ or $\mathrm{p} 38 \delta$ had no significant effect on the formation of apoptotic cells induced by $\mathrm{Zn}-\mathrm{BC}-\mathrm{AM}$ PDT. The result from this study is consistent with the enhancement of apoptosis by SB203580 in PDTtreated HK-1 cells (Figure 5C and 5D).

\section{Effects of PD98059 on Zn-BC-AM PDT-induced ERK phosphorylation and apoptosis}

In addition to p38 MAPK and JNK, the expression of phosphorylated ERK (p-ERK) was also increased after Zn-
99

100

101

102

103

104

105

106

107

108

109

110

111

112

113

114

115

116

117

118

119

120

121 


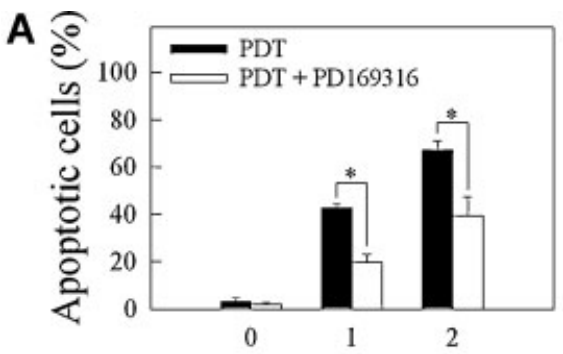

Light Dose $\left(\mathrm{J} / \mathrm{cm}^{2}\right)$

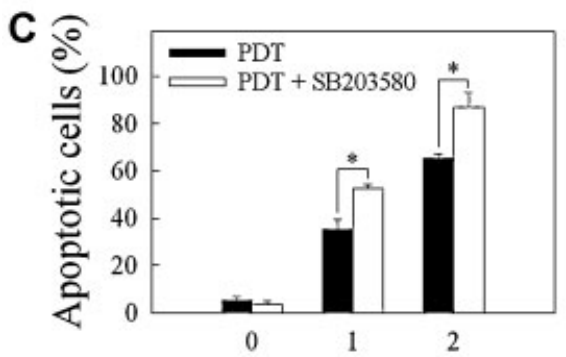

Light Dose $\left(\mathrm{J} / \mathrm{cm}^{2}\right)$

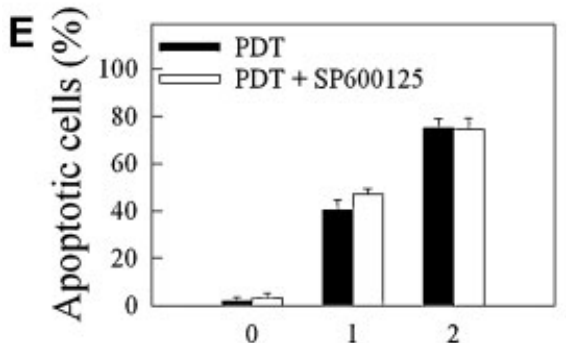

Light Dose $\left(\mathrm{J} / \mathrm{cm}^{2}\right)$
B

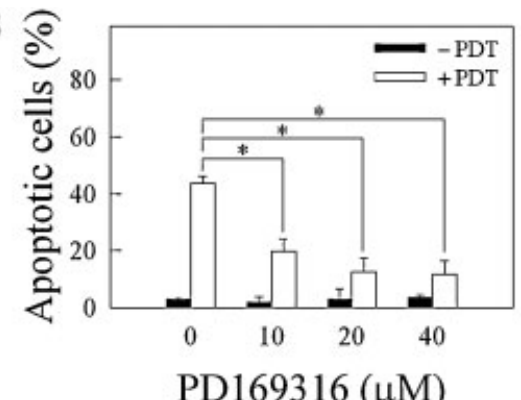

D

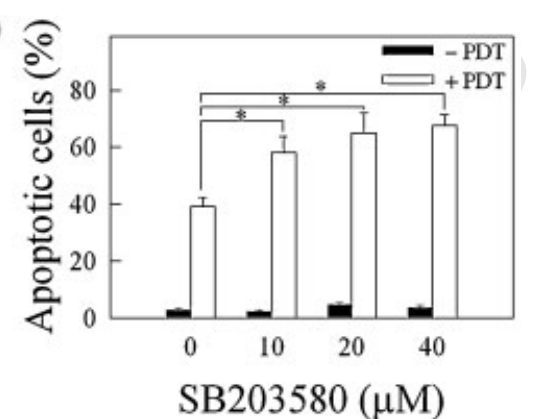

$F$

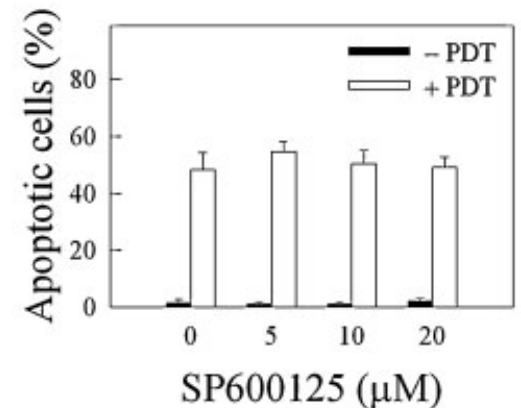

G

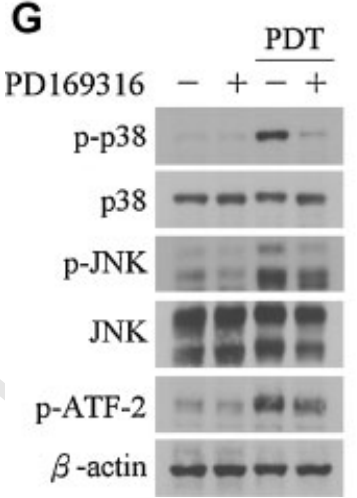

H

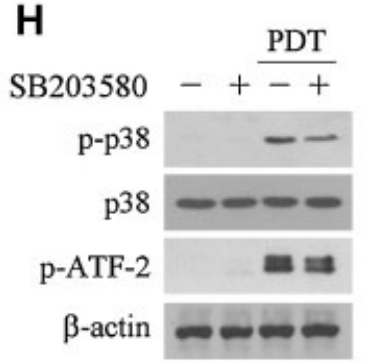

I

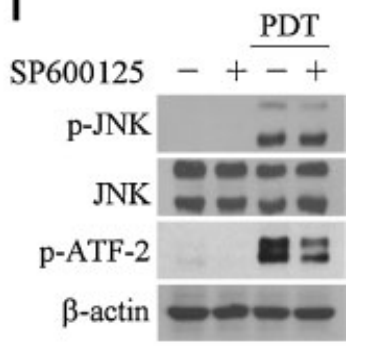

100

101

102

103

104

105

106

107

108

109

110

111

112

113

Figure 5. Effect of PD169316, SB203580 and SP600125 on Zn-BC-AM PDT-induced apoptosis. Zn-BC-AM-loaded HK-1 cells were pre-treated with $10 \mu M$ PD169316 (A), $10 \mu \mathrm{M}$ SB203580 (C) or $5 \mu \mathrm{M}$ SP600125 (E) for $1 \mathrm{~h}$ before light irradiation ( 1 and $2 \mathrm{~J} / \mathrm{cm}^{2}$ ). Effect of various doses of PD169316 (B), SB203580 (D) and SP600125 (F) on the production of apoptotic cells. Cells were irradiated at $1 \mathrm{~J} / \mathrm{cm}^{2}$. Percentage of apoptotic cells were expressed as mean $\pm \mathrm{SD}(n=3)$. ${ }^{*} p<0.05$ versus PDT control. Effect of various inhibitors on the expression $\mathrm{p}-\mathrm{p} 38, \mathrm{p}-\mathrm{JNK}$ and their downstream target ATF-2 at $10 \mathrm{~min}$ post-PDT $\left(1 \mathrm{~J} / \mathrm{cm}^{2}\right)(\mathrm{G}$, $\mathrm{H}$ and $\mathrm{I})$. The concentrations of inhibitors used in this study were the same as $\mathrm{A}, \mathrm{C}$ and $\mathrm{E}$.

BC-AM PDT (Figure 3). The effect of MEK/ERK inhibitor PD98059 on Zn-BC-AM PDT-induced apoptosis was then examined. The expression of p-ERK in PDT-treated HK-1 cells was significantly reduced by PD98059 (Figure 7A).
The basal expression level of p-ERK was also reduced by PD98059. In the functional study, PD98059 dose dependently enhanced PDT-induced apoptosis of HK-1 cells (Figure 7B). 
A

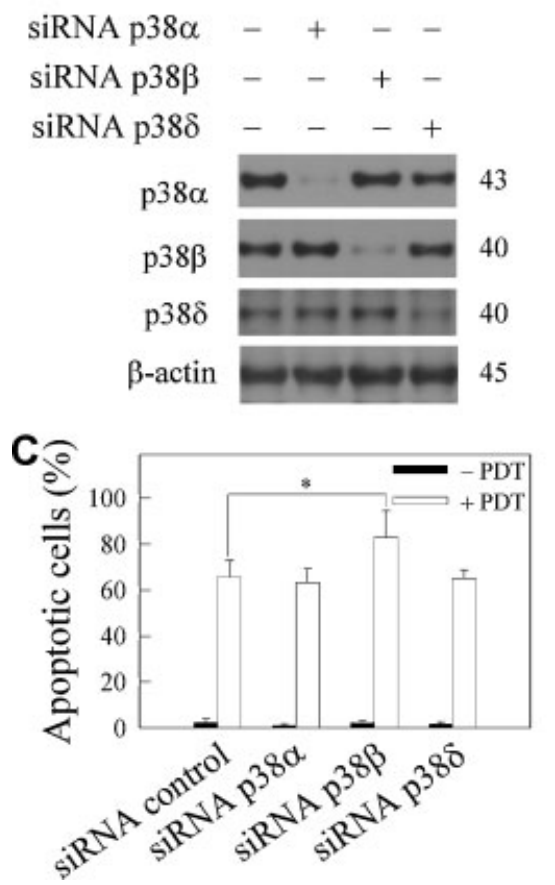

B

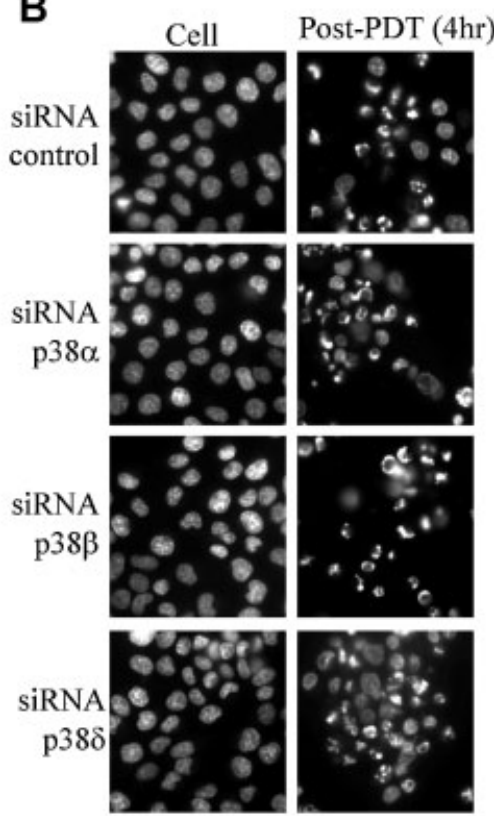

Figure 6. Effect of knockdown of the p38 $\alpha$, p38 $\beta$ and $\mathrm{p} 38 \delta$ isoforms on the formation of apoptotic cells induced by $\mathrm{Zn}-\mathrm{BC}-\mathrm{AM}$ PDT. HK-1 cells $\left(1.5 \times 10^{5}\right)$ were grown overnight and then transiently transfected with siRNA-transfecting reagent complexes as described in Materials and Methods. (A) Specificity of siRNA p38 MAPK isoforms. Expression of the corresponding p38 MAPK isoforms was determined by Western Blot. (B) Transfected cells were incubated with or without Zn-BC-AM (1 $\mu \mathrm{M})$ for $24 \mathrm{~h}$. Medium was replaced with fresh medium before light irradiation. The cells were stained with Hoechst 33342 for 30 min before harvesting. Fluorescence images were captured under a fluorescence microscope at $4 \mathrm{~h}$ post-PDT. (C) Percentage of apoptotic cells. At least 300 cells for each treatment were counted. Results were expressed as the mean $\pm \mathrm{SD}(n=3) .{ }^{*} p<0.05$ versus PDT siRNA control.

\section{DISCUSSION}

MAPKs are involved in a wide range of cellular activities. These include the cell growth and proliferation, differentiation, cell movement and cell death in response to various stimuli and stresses. ${ }^{1}$ ERK pathway is generally activated by mitogens and growth factors while p38 MAPK and JNK pathways are activated in response to chemical stimuli and environmental stresses. In addition, activation of MAPKs by different stresses such as UV $\mathrm{UV}^{27-31}$ and heat ${ }^{32}$ also leads to apoptosis. Hence, MAPKs play an important role in the apoptotic signalling pathways. Many chemotherapeutic agents are known to induce tumour cell death via the modulation of the MAPKs signalling pathways. For example, microtubule inhibitors (vinca alkaloids and paclitaxel) induce a sustained activation of JNK in many tumour cells. ${ }^{33-35}$ Cisplatin, a DNA-damaging chemotherapeutic drug, activates p38 MAPK in ovarian carcinoma cells before the onset of apoptosis. ${ }^{36}$ Hence, the response of the MAPK signalling pathways to PDT is complex. ${ }^{37}$

Therapeutic effect of PDT basically relies on the generation of reactive oxygen species by the photoactivated photosensitizers. Since MAPKs are sensitive to oxidative stress, we hypothesize that MAPKs are also involved in $\mathrm{Zn}$ BC-AM PDT-induced apoptosis of NPC cells. We have previously demonstrated that PDT induces apoptosis in undifferentiated NPC cells. ${ }^{38-41}$ In the present study, we further demonstrated the role of MAPKs in Zn-BC-AM PDT-induced apoptosis of the well-differentiated NPC cells. Zn-BC-AM PDT was found to enhance phosphorylation activation of all three major MAPKs, namely p38 MAPK, JNK and ERK, immediately after PDT. Using two different approaches, namely pharmacological inhibition with p38 MAPK inhibitor SB203580 and knockdown the expression of $\mathrm{p} 38 \beta$ with siRNA, we found that inhibition of phosphorylation of $\mathrm{p} 38 \beta$ would enhance Zn-BC-AM PDT-induced apoptosis of HK-1 cells. Differential role of p38 MAPK isoforms has previously been reported in certain studies of apoptotic cell death. Translational knockdown of $\mathrm{p} 38 \alpha$ was found to diminish the death receptor-mediated cleavage of caspase- 3 in Jurkat cells. In contrast, knockdown of p38 $\beta$ sensitized the cells to apoptosis in the same cell model. ${ }^{42} \mathrm{On}$ the other hand, inhibition of $\mathrm{p} 38 \alpha$ would prevent the death of cardiomyocytes caused by a combination of prolonged hypoxia followed by reoxygenation, while $\mathrm{p} 38 \beta$ exerted a protective role in response to the hypoxic stress. ${ }^{43}$ Although p38 is preferentially expressed in keratinocytes ${ }^{25}$ and p38 $\delta$ is also detected in HK-1 cell, knockdown of $\mathrm{p} 38 \delta$ shows no significant effect on PDT-induced apoptosis of HK-1 cells. These observations suggested that the $\mathrm{p} 38 \beta$ may be a potential therapeutic target to enhance the efficacy of PDTinduced apoptosis of NPC cells. 
A

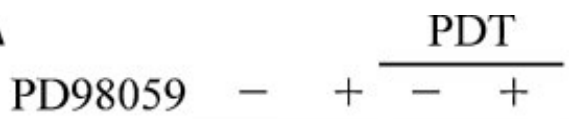
p-ERK

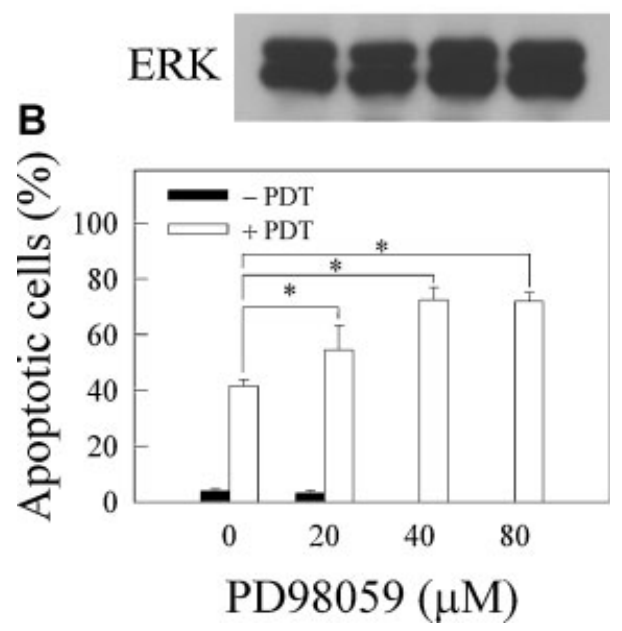

Figure 7. Effect of PD98059 on PDT-induced apoptosis. HK-1 cells $\left(3 \times 10^{5}\right)$ in $35 \mathrm{~mm}$ petri dish were grown overnight and then incubated with $\mathrm{Zn}$-BC-AM $(1 \mu \mathrm{M})$ for 24 hours. The cells were then treated with MEK/ERK inhibitor PD98059 $(40 \mu \mathrm{M})$ for $1 \mathrm{~h}$ before light irradiation. (A) Effect of PD 98059 on the expression of phosphorylated ERK in PDT-treated HK-1 cells. Cell lysates were collected at $10 \mathrm{~min}$ post-PDT $\left(1 \mathrm{~J} / \mathrm{cm}^{2}\right)$. (B) Dose dependent augmentation of PDT-induced production of apoptotic cells by PD98059. Apoptotic cell count was performed at $4 \mathrm{~h}$ post-PDT. Results were expressed as mean $\pm \mathrm{SD}(n=3) .{ }^{*} p<0.05$ versus PDT control.

In the functional studies, pharmacological inhibitors PD169316 and SB203580 are frequently used as p38 MAPK inhibitor. ${ }^{4-46}$ In the present study, although PD169316 and SB203580 inhibit the phosphorylation of p38 MAPK and the downstream target ATF-2, these two inhibitors exert an opposing effect in PDT-treated HK-1 cells. The discrepancy in the action between PD169316 (anti-apoptotic) and SB203580 (apoptosis enhancing) in PDT-treated HK-1 cells is unknown. Specificity of chemical inhibitors is always a concern especially in the cellular system when the inhibitors were used at the range of micromolar concentrations. p38 MAPK inhibitors had previously been shown to inhibit many enzymes outside of the MAPK family. ${ }^{47}$ The anti-apoptotic effect of PD169316 might be due to the off-target effect of the inhibitors in the HK-1 cells. The possible action of PD169316 in PDT-treated NPC cells is currently under investigation.

Apart from $\mathrm{p} 38 \beta$, the ERK inhibitor PD98059 also enhanced the production of apoptotic cells after Zn-BC-AM PDT. ERK is generally considered as a survival kinase involved in the control of cell growth. Unlike p38 MAPKs and JNK, p-ERK is constitutively expressed in the HK-1 cells. It is interesting to note that PD98059 also inhibits the basal expression level of p-ERK in the control HK-1 cells. However, the viability of the cell was not affected. This may be explained by the fact that other signalling pathways such as PI3K/AKT and NF- $\kappa \mathrm{B}$ are also involved in the regulation of cell survival. In the PDT-treated HK-1 cells, p-ERK appears to counteract PDT-induced apoptosis as inhibition of the expression of p-ERK results in augmentation of PDTinduced apoptosis of HK-1. This explanation is supported by the previous observation that sustained activation of ERK1/2 would protect cells from PDT-induced damage. ${ }^{16}$

Combination of p38 MAPK inhibitor and PDT in clinical application is worthy for discussion. First of all, inhibition of specific p38 isoform can directly enhance apoptosis of PDTtreated tumour cells. Secondly, p38 MAPK inhibition may indirectly control the growth of tumour cells. A recent study showed that p38 MAPK inhibitor would suppress PDTinduced VEGF production. ${ }^{48} \mathrm{VEGF}$ is one of the key angiogenic factors and anti-angiogenesis is a strategy currently used in cancer therapy. Combination of PDT and selective p38 MAPK inhibition might enhance the efficacy of the treatment. However, this treatment approach needs to further be tested in the animal model.

In summary, we demonstrated that Zn-BC-AM PDTinduced apoptosis in the well differentiated HK-1 NPC cells could be enhanced by the inhibition of $\mathrm{p} 38 \beta$ isoform and ERK. The protective effect of PD169316 in Zn-BC-AM PDT-induced apoptosis of the HK-1 cells is likely beyond the action on p38 MAPK and JNK. The use of PD169316 as the $338 \mathrm{MAPK} / \mathrm{JNK}$ inhibitor for the investigation of the apoptotic cell death should be in caution. Other methods such as siRNA are recommended to be used in parallel to the chemical inhibitors.

\section{ACKNOWLEDGEMENTS}

This work was supported by the Research Grants Council of Hong Kong (project no. HKBU 2458/06M) and the Faculty Development Grant (no. FRG/07-08/I-57).

\section{REFERENCES}

1. Johnson GL, Lapadat R. Mitogen-activated protein kinase pathways mediated by ERK, JNK, and p38 protein kinases. Science 2002; 298: 1911-1912.

2. Davies ${ }^{\mathrm{Q} 6} \mathrm{SP}$, Reddy H, Caivano M, et al. Specificity and mechanism of action of some commonly used protein kinase inhibitors. Biochem $J$ 2000; 351: 95-105.

3. Kyriakis JM, Avruch J. Mammalian mitogen-activated protein kinase signal transduction pathways activated by stress and inflammation. Physiol Rev 2001; 81: 807-869.

4. Lewis TS, Shapiro PS, Ahn NG. Signal transduction through MAP kinase cascades. Adv Cancer Res 1998; 74: 49-139.

5. Buytaert E, Dewaele M, Agostinis P. Molecular effectors of multiple cell death pathways initiated by photodynamic therapy. Biochim Biophys Acta 2007; 1776: 86-107.

6. Agostinis P, Buytaert E, Breyssens H, et al. Regulatory pathways in photodynamic therapy induced apoptosis. Photochem Photobiol Sci 2004; 3: 721-729.

7. Moor AC. Signaling pathways in cell death and survival after photodynamic therapy. J Photochem Photobiol B 2000; 57: 1-13.

8. Xue L, He J, Oleinick NL. Promotion of photodynamic therapyinduced apoptosis by stress kinases. Cell Death Differ 1999; 6: 855864. 
9. Assefa Z, Vantieghem A, Declercq W, et al. The activation of the c-Jun $\mathrm{N}$-terminal kinase and p38 mitogen-activated protein kinase signaling pathways protects HeLa cells from apoptosis following photodynamic therapy with hypericin. J Biol Chem 1999; 274: 8788-8796.

10. Klotz LO, Fritsch C, Briviba K, et al. Activation of JNK and p38 but not ERK MAP kinases in human skin cells by 5-aminolevulinate-photodynamic therapy. Cancer Res 1998; 58: 4297-4300.

11. Wong TW, Tracy E, Oseroff AR, et al. Photodynamic therapy mediates immediate loss of cellular responsiveness to cytokines and growth factors. Cancer Res 2003; 63: 3812-3818.

12. Tao J, Sanghera JS, Pelech SL, et al. Stimulation of stress-activated protein kinase and 38 HOG1 kinase in murine keratinocytes following photodynamic therapy with benzoporphyrin derivative. J Biol Chem 1996; 271: 27107-27115.

13. Kralova J, Dvorak M, Koc M, et al. p38 MAPK plays an essential role in apoptosis induced by photoactivation of a novel ethylene glycol porphyrin derivative. Oncogene 2007.

14. Chan WH, Wu HJ. Anti-apoptotic effects of curcumin on photosensitized human epidermal carcinoma A431 cells. J Cell Biochem 2004; 92 : 200-212.

15. Weyergang A, Kaalhus O, Berg K. Photodynamic therapy with an endocytically located photosensitizer cause a rapid activation of the mitogen-activated protein kinases extracellular signal-regulated kinase, p38, and c-Jun NH2 terminal kinase with opposing effects on cell survival. Mol Cancer Ther 2008; 7: 1740-1750.

16. Tong Z, Singh G, Rainbow AJ. Sustained activation of the extracellular signal-regulated kinase pathway protects cells from photofrin-mediated photodynamic therapy. Cancer Res 2002; 62: 5528-5535.

17. Mak NK, Li KM, Leung WN, et al. Involvement of both endoplasmic reticulum and mitochondria in photokilling of nasopharyngeal carcinoma cells by the photosensitizer Zn-BC-AM. Biochem Pharmacol 2004; 68: 2387-2396.

18. Huang DP, Ho JH, Poon YF, et al. Establishment of a cell line (NPC/ HK1) from a differentiated squamous carcinoma of the nasopharynx. Int J Cancer 1980; 26: 127-132.

19. Tsai T, Hong RL, Tsai JC, et al. Effect of 5-aminolevulinic acidmediated photodynamic therapy on MCF-7 and MCF-7/ADR cells. Lasers Surg Med 2004; 34: 62-72.

20. Yamamoto K, Ichijo H, Korsmeyer SJ. BCL-2 is phosphorylated and inactivated by an ASK1/Jun N-terminal protein kinase pathway normally activated at G(2)/M. Mol Cell Biol 1999; 19: 8469-8478.

21. Han J, Lee JD, Bibbs L, et al. A MAP kinase targeted by endotoxin and hyperosmolarity in mammalian cells. Science 1994; 265: 808-811.

22. Jiang Y, Chen C, Li Z, et al. Characterization of the structure and function of a new mitogen-activated protein kinase (p38beta). J Biol Chem 1996; 271: 17920-17926.

23. Jiang $\mathrm{Y}$, Gram $\mathrm{H}$, Zhao M, et al. Characterization of the structure and function of the fourth member of $\mathrm{p} 38$ group mitogen-activated protein kinases, p38delta. J Biol Chem 1997; 272: 30122-30128.

24. Li Z, Jiang Y, Ulevitch RJ, et al. The primary structure of p38 gamma: a new member of p38 group of MAP kinases. Biochem Biophys Res Coтmun 1996; 228: 334-340.

25. Eckert RL, Efimova T, Balasubramanian S, et al. p38 Mitogen-activated protein kinases on the body surface-a function for p38 delta. J Invest Dermatol 2003; 120: 823-828.

26. Martin-Blanco E. p38 MAPK signalling cascades: ancient roles and new functions. Bioessays 2000; 22: 637-645.

27. Assefa Z, Vantieghem A, Garmyn M, et al. p38 mitogen-activated protein kinase regulates a novel, caspase-independent pathway for the mitochondrial cytochrome $\mathrm{c}$ release in ultraviolet $\mathrm{B}$ radiation-induced apoptosis. J Biol Chem 2000; 275: 21416-21421.

28. Bodero AJ, Ye R, Lees-Miller SP. UV-light induces p38 MAPKdependent phosphorylation of Bcl10. Biochem Biophys Res Commun 2003; 301: 923-926.
29. Merienne K, Jacquot S, Zeniou M, et al. Activation of RSK by UVlight: phosphorylation dynamics and involvement of the MAPK pathway. Oncogene 2000; 19: 4221-4229.

30. Takekawa M, Adachi M, Nakahata A, et al. p53-inducible wip1 phosphatase mediates a negative feedback regulation of p38 MAPKp53 signaling in response to UV radiation. EMBO J 2000; 19: 65176526.

31. Tanos T, Marinissen MJ, Leskow FC, et al. Phosphorylation of c-Fos by members of the p38 MAPK family. Role in the AP-1 response to UV light. J Biol Chem 2005; 280: 18842-18852.

32. Pantos C, Malliopoulou V, Mourouzis I, et al. Involvement of p38 MAPK and JNK in heat stress-induced cardioprotection. Basic Res Cardiol 2003; 98: 158-164.

33. Boldt S, Weidle UH, Kolch W. The role of MAPK pathways in the action of chemotherapeutic drugs. Carcinogenesis 2002; 23: 18311838 .

34. Olson JM, Hallahan AR. p38 MAP kinase: a convergence point in cancer therapy. Trends Mol Med 2004; 10: 125-129.

35. Stone AA, Chambers TC. Microtubule inhibitors elicit differential effects on MAP kinase (JNK, ERK, and p38) signaling pathways in human KB-3 carcinoma cells. Exp Cell Res 2000; 254: 110-119.

36. Chen Z, Seimiya H, Naito M, et al. ASK1 mediates apoptotic cell death induced by genotoxic stress. Oncogene 1999; 18: 173-180.

37. $\mathrm{Mak}^{\mathrm{Q7}} \mathrm{NK}$, Lung ML, Chang CK, et al. Photosensitizers as novel compounds in apoptosis research. In New Developments in Cell Apoptosis Research, Corvin AJ (ed.). Nova Science Publishers, Inc, 2006; 241-272.

38. Li KM, Sun X, Koon HK et al. Apoptosis and expression of cytokines triggered by pyropheophorbide-a methyl ester-mediated photodynamic therapy in nasopharyngeal carcinoma cells. Photodiagnosis Photodyn Ther 2006; 247-258

39. Mak NK, Kok TW, Wong RN et al. Photodynamic activities of sulfonamide derivatives of porphycene on nasopharyngeal carcinoma cells. J Biomed Sci 2003; 10: 418-429.

40. Yow CM, Chen JY, Mak NK et al. Cellular uptake, subcellular localization and photodamaging effect of temoporfin (mTHPC) in nasopharyngeal carcinoma cells: comparison with hematoporphyrin derivative. Cancer Lett 2000; 157: 123-131.

41. Yow CM, Mak NK, Szeto S et al. Photocytotoxic and DNA damaging effect of temoporfin (mTHPC) and merocyanine 540 (MC540) on nasopharyngeal carcinoma cell. Toxicol Lett 2000; 115: 53-61.

42. Tourian L, Jr., Zhao H, Srikant CB. p38alpha, but not $\mathrm{p} 38$ beta, inhibits the phosphorylation and presence of c-FLIPS in DISC to potentiate Fasmediated caspase-8 activation and type I apoptotic signaling. $J$ Cell Sci 2004; 117: 6459-6471.

43. Kim JK, Pedram A, Razandi M et al. Estrogen prevents cardiomyocyte apoptosis through inhibition of reactive oxygen species and differential regulation of p38 kinase isoforms. J Biol Chem 2006; 281: 6760-6767.

44. Fragoso G, Haines JD, Roberston J et al. p38 mitogen-activated protein kinase is required for central nervous system myelination. Glia 2007; 55: 1531-1541.

45. Samuvel DJ, Jayanthi LD, Bhat NR et al. A role for p38 mitogenactivated protein kinase in the regulation of the serotonin transporter: evidence for distinct cellular mechanisms involved in transporter surface expression. $J$ Neurosci 2005; 25: 29-41.

46. Trouillas M, Saucourt C, Duval D et al. Bcl2, a transcriptional target of p38alpha, is critical for neuronal commitment of mouse embryonic stem cells. Cell Death Differ 2008; 15: 1450-1459.

47. Norris JL, Williams KP, Janzen WP et al. Selectivity of SB203580, SB202190 and other commonly used p38 inhibitors: profiling against a multi-enzyme panel. Lett Drug Des Discov 2005; 2: 516-521.

48. Solban N, Selbo PK, Sinha AK et al. Mechanistic investigation and implications of photodynamic therapy induction of vascular endothelial growth factor in prostate cancer. Cancer Res 2006; 66: 5633-5640. 